\title{
High complete resection rate for pre-lift and cold biopsy of diminutive colorectal polyps
}

\section{()(1) $\ominus$}

\section{Authors}

Sam A. O'Connor ${ }^{1,2}$, Trevor N. Brooklyn², Paul D. Dunckley ${ }^{4}$, Roland M. Valori ${ }^{4}$, Ruth Carr ${ }^{2}$, Chris Foy ${ }^{5}$, Thusitha Somarathna ${ }^{3}$, Lukasz A. Adamczyk ${ }^{3}$, Neil A. Shepherd ${ }^{3}$, John T. Anderson²

\section{Institutions}

1 Department of Gastroenterology and Hepatology, Princess Alexandra Hospital, Ipswich Rd, Woolloongabba, Queensland, Australia

2 Department of Gastroenterology, Cheltenham General Hospital, Sandford Road, Cheltenham, UK

3 Gloucestershire Cellular Pathology Laboratory, Cheltenham General Hospital, Sandford Road, Cheltenham, UK

4 Department of Gastroenterology, Gloucestershire Royal Hospital, Great Western Rd, Gloucester, UK

5 Research and Development Unit, Gloucestershire NHS Hospitals Trust, Gloucester, UK

submitted 29.11.2016

accepted after revision 8.9.2017

Bibliography

DOI https://doi.org/10.1055/s-0043-121874 |

Endoscopy International Open 2018; 06: E173-E178

(c) Georg Thieme Verlag KG Stuttgart · New York

ISSN 2364-3722

Corresponding author

Dr Sam A. O'Connor MBBS (Hon), FRACP, Princess

Alexandra Hospital, 199 Ipswich Rd, Woolloongabba QLD,

Australia 4102

oconnorsama@gmail.com

\section{ABSTRACT}

Background and study aims The majority of polyps removed at colonoscopy are diminutive $(\leq 5 \mathrm{~mm})$ to small $(<10 \mathrm{~mm})$ and there are few guidelines for the best way for these polyps to be removed. We aimed to assess the feasibility and effectiveness of cold biopsy forceps polypectomy with pre-lift (CBPP) for polyps $\leq 7 \mathrm{~mm}$. Our aims were to assess completeness of histological resection of this technique, to identify factors contributing to this and assess secondary considerations such as timing, retrieval and complication rates.

Patients and methods We conducted a prospective cohort study on consecutive patients receiving a colonoscopy at Cheltenham General Hospital, as part of the National Bowel Cancer Screening Program (BCSP) in England. The study included only polyps that were judged as $\leq 7 \mathrm{~mm}$ by the colonoscopist. A small sub-mucosal pre-lift injection was administered prior to removal of the polyp using cold biopsy forceps. One or more biopsies were taken until the polyp was confidently assessed visually as being completely removed by the colonoscopist. The entire polypectomy site was then removed en bloc by endomucosal resection (EMR) with a margin of at least 1 to $2 \mathrm{~mm}$ around defect. This was sent for histopathological analysis to assess completeness of resection. Polypectomy timing, tissue retrieval, number of bites required for visual resection and complications were recorded at the time of the procedure.

Results Sixty-four patients were recruited and consented. Of them, 42 patients had a total of 60 polyps resected. Three patients had inflammatory polyps and were excluded from the study, leaving 57/60 polyps for final analysis. Seventeen were hyperplastic and 40 adenomatous polyps. Retrieval was complete for all 57 polyps and there were no complications both during or post- polypectomy. The complete resection rate (CRR) was $86 \%$. The technique was more effective in smaller polyps with $91.7 \%$ of diminutive polyps $(\leq 5 \mathrm{~mm}$ ) completely excised.

Conclusions CBPP is a safe and highly effective technique for polyps $<5 \mathrm{~mm}$ with a high complete resection and retrieval rate. The time taken for the procedure is significantly greater than cold forceps alone, or cold snare as seen in other studies.

\section{Introduction}

Colonoscopy and polypectomy reduces morbidity and mortality associated with colorectal cancer [1-3]. Up to $27 \%$ of interval colorectal cancers are at the site of incomplete polypectomy
[4-7], emphasizing the importance of complete histological resection of pre-malignant lesions.

The colonoscopist decides which technique to use for the removal of these premalignant lesions. Individual approach and 
technique employed is not standardised, especially with smaller lesions. Surveys of colonoscopists and gastroenterologists in Australia and the United States show that the choice of method used for diminutive to small polyps is highly variable with cold snaring marginally reported as the preferred overall method [8, 9].

Studies have shown the adequacy of cold forceps polypectomy for diminutive polyps $\leq 3 \mathrm{~mm}$ [10-12]. Studies also show that lesions greater than this size are inadequately resected by this method and suggested a snare polypectomy should be used $[10-14]$.

Guidelines for removal of diminutive $(\leq 5 \mathrm{~mm})$ to small (6$9 \mathrm{~mm}$ ) polyps are limited despite the fact that the majority of polyps found during colonoscopy are diminutive [15-17]. Several studies reveal that $9 \%$ to $10 \%$ of diminutive colorectal polyps can have advanced histology $[18,19]$. The American Society of Gastrointestinal Endoscopy does not have published guidelines for such polyps. The European society of gastrointestinal endoscopy (ESGE) bowel cancer screening guidelines from 2012 state that polyps $<5 \mathrm{~mm}$ should be removed by cold biopsy forceps or by cold snaring and polyps $\geq 5 \mathrm{~mm}$ should be snared [20]. Newer ESGE guidelines state that all polyps 0 to $9 \mathrm{~mm}$ should be cold snared and cold forceps only be considered in technically difficult polyps that are $1-3 \mathrm{~mm}$ [17].

Our aim was to assess feasibility of a novel method of polypectomy for polyps $\leq 7 \mathrm{~mm}$. A small pre-lift was used prior to resection of polyps with cold biopsy forceps or cold biopsy forceps polypectomy with pre-lift (CBPP). We hypothesize that this method will have a complete resection rate $>90 \%$ with a $100 \%$ retrieval rate in polyps $\leq 5 \mathrm{~mm}$. Polyps measuring 6 to $7 \mathrm{~mm}$ were also included for assessment. This technique falls outside the previously mentioned new ESGE guidelines but each polypectomy site was resected en bloc ensuring complete histological resection of a polyp.

The main objective of the study was to determine the histological complete resection rate (CRR) for this technique and any factors that may influence this.

\section{Patients and methods}

\section{Study design/setting}

We conducted a prospective observational study in patients undergoing colonoscopy at Cheltenham General Hospital and Gloucestershire Royal Hospital. The study was reviewed and approved by the Gloucestershire NHS Trust Research and Development team and East Midlands Division of the National Research Ethics Service (NRES). The study was registered with www.clinicaltrials.gov (NCT02354287). We followed the 'strengthening the reporting of observational studies in epidemiology' (STROBE) guidelines in reporting our findings [21].

\section{Patients and polyps}

All patients were undergoing outpatient colonoscopy at the Cheltenham General Hospital and Gloucestershire Royal Hospitals as part of the English BCSP. Consecutive patients were recruited between February and September 2015 and informed consent obtained prior to their Colonoscopy. All patients were followed up the day after their procedure and later when histology results became available. Patient details including age, sex and indication (screening or surveillance) was recorded.

Patients were excluded if they:

1. were under the age of 18 ;

2. did not have capacity to consent for the colonoscopy as determined at the time of procedural admission by the trained admitting endoscopy nurse;

3. had a history of inflammatory bowel disease;

4. had identified coagulopathy with prothrombin time $>1.4$ or thrombocytopenia with platelets $<80$ on any bloods collected within routine clinical practice within the past 4 weeks;

5. to dual antiplatelet therapy or pharmacological anti-coagulation; or

6. had bowel preparation deemed poor by the colonoscopist.

Polyps were assessed at the time of colonoscopy to determine suitability. They were required to be $\leq 7 \mathrm{~mm}$ as judged by comparison with biopsy forceps that had a span when open of 6.8 $\mathrm{mm}$. This gave a reasonably accurate estimation of the upper limit of polyp size. Biopsy forceps when closed had a span of $2.4 \mathrm{~mm}$ and helped give an approximation of size for the diminutive polyps $(1-5 \mathrm{~mm})$ in the study. No more than 3 polyps were removed in any 1 patient for study inclusion in an attempt to limit procedural times and any chance of complications for those patients included in the study. If a different technique was determined to be more appropriate by the colonoscopist because of anatomical location, polyp morphology or other factors, than the polyp was not included in the study.

\section{Colonoscopists}

All colonoscopies and polypectomies were performed by 2 (JA, TB) highly experienced ( $>10,000$ colonoscopies) certified Bowel Cancer Screening Program colonoscopists.

\section{Procedure}

Colonoscopies were performed using Olympus (Olympus Medical Systems Corporation, Tokyo, Japan) 240, 260 and 290 colonoscopes with magnetic endoscopic imaging (ScopeGuide) and Narrow band imaging (NBI) available to the Colonoscopist. Near focus was also available to be used on the 290 scopes. Bowel preparation used was standard split dose polyethylene glycol (PEG) or combination split dose PEG and sodium picosulfate. Bowel preparation was assessed as good, adequate or poor by the colonoscopist. If a polyp was deemed appropriate for resection a small pre-lift using solution containing gelafusin, adrenaline and indigo carmine (Mix ratio of: $19 \mathrm{~mL}$ Gelafusin, $1 \mathrm{~mL}$ 1:10000 adrenaline, $1 \mathrm{ml}$ indigo carmine) was performed. This solution was routinely used and available for all bowel cancer screening colonoscopy lists at these facilities. The polyp was determined to be appropriately lifted when the lateral margins could be defined and seen to clearly have lift under them. The polyp was then resected with cold biopsy forceps until complete visual eradication ( $>$ Fig. 1, $\triangleright$ Fig. 2, $>$ Fig.3, $>$ Fig.4). $\mathrm{NBI}$ and image magnification were used at the discretion of the colonoscopists. EMR of the polypectomy site with a rim of normal tissue of at least $2 \mathrm{~mm}$ was performed using a 10 or 1 


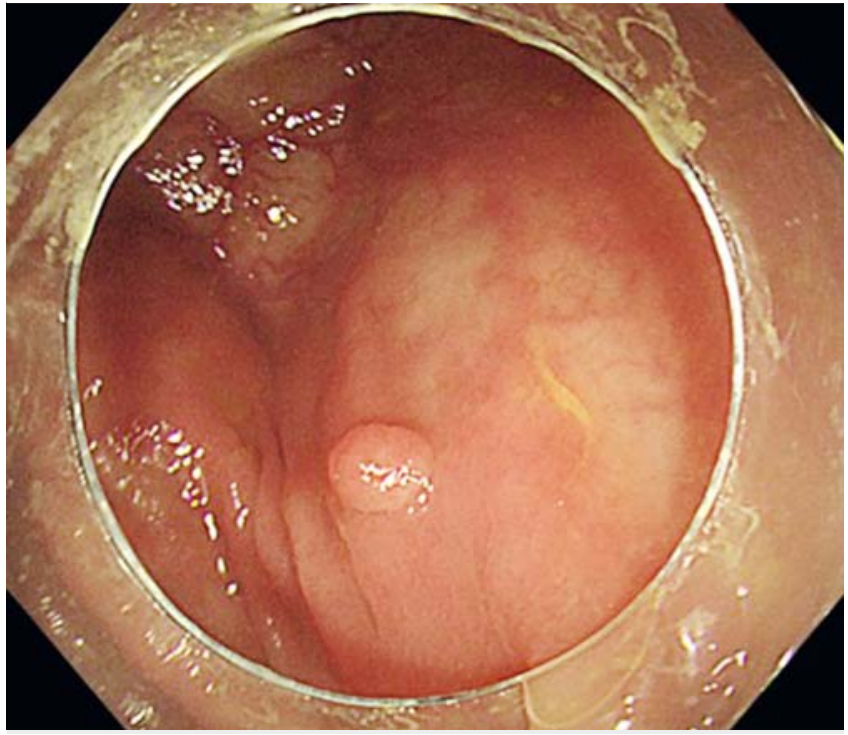

- Fig. 1 Polypectomy technique. A 3-mm polyp pre-lift.

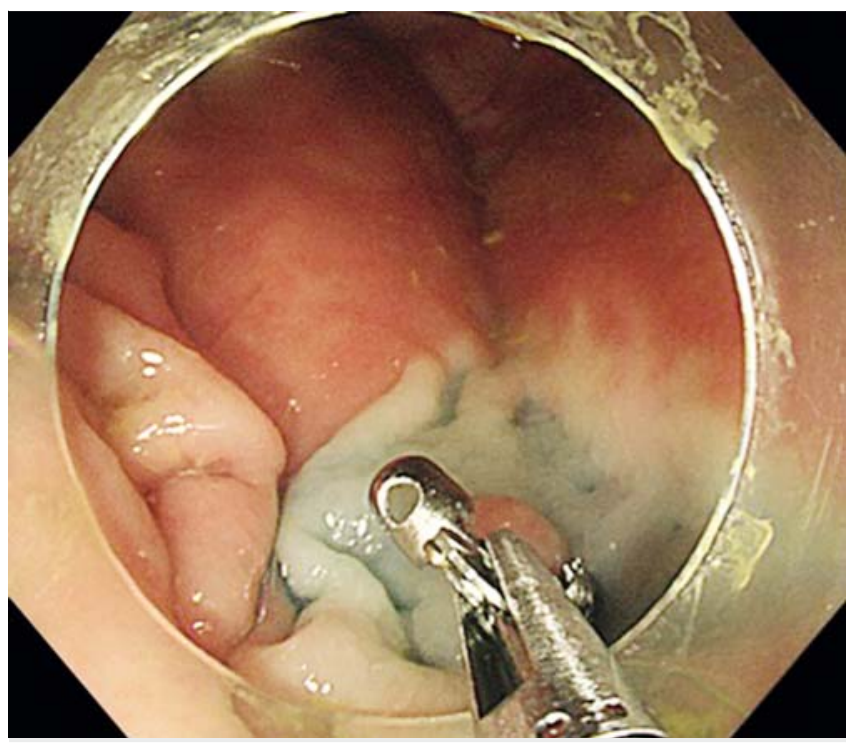

Dig. 3 Polypectomy with standard cold forceps.

$5 \mathrm{~mm}$ braided snare. The exact site of polypectomy was judged by colonoscopist with the aid of magnetic endoscope imager and recorded. The EMR specimen was numbered and correlated with polyp before both were sent for review. EMR specimen was de-identified. Polyps were sent for histology review in the standard manner.

Other variables studied included timing and number of bites required for complete visual resection, retrieval and complication rates. The timing from the point of pre-lift needle insertion till complete visual eradication of polyp with forceps was recorded. Bites for visual eradication, retrieval and complication rate for each polypectomy was recorded. Complete procedure and withdrawal times were recorded.

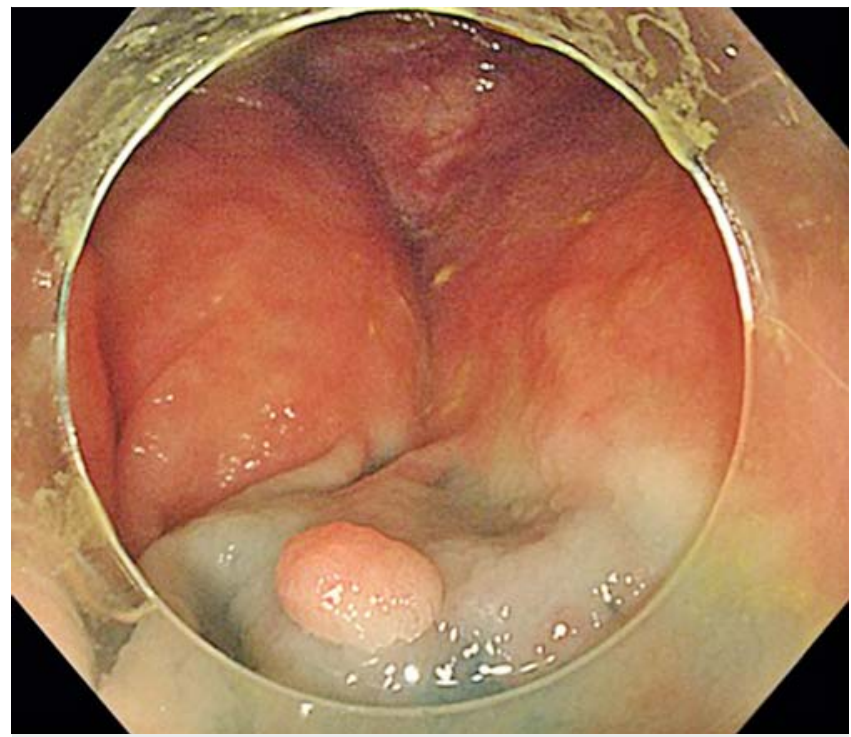

Fig. 2 Polyp post-lift.

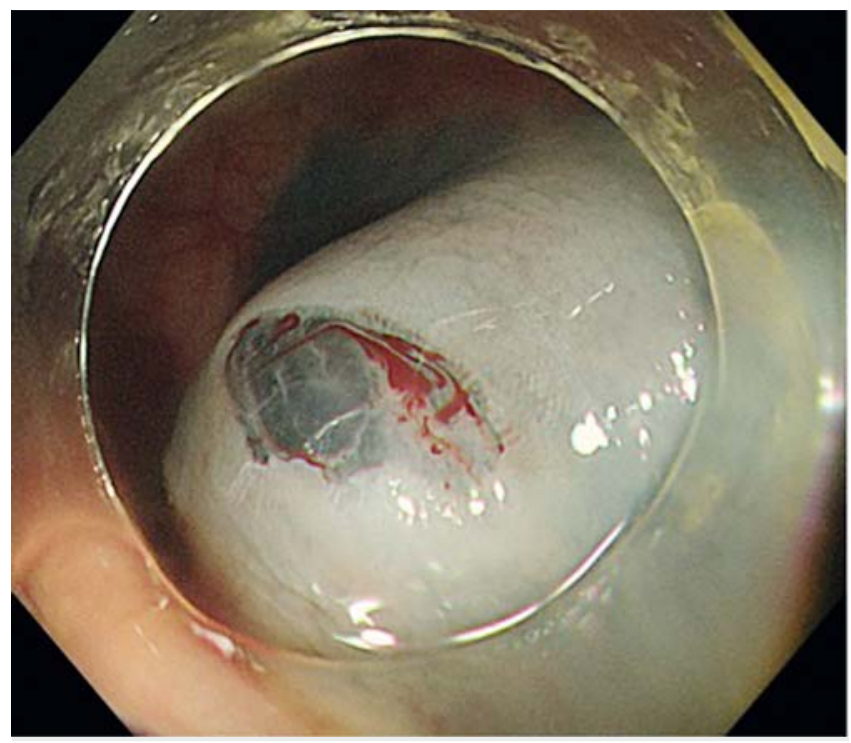

> Fig. 4 Post-polypectomy.

\section{Pathological assessment}

Each polyp itself was submitted for routine pathological assessment, with three levels cut through each block, whilst the subsequent EMR was submitted for histology in its entirety and levels cut at 5 microns right through each block. Thus the EMR specimen was assessed in its entirety for any polyp remnants. The polyp slides were assessed routinely whilst the slides from the EMR specimens were assessed independently by one expert gastrointestinal pathologist (NAS) and by two fellows (TS \& LAA). All three observers were blinded to patient and colonoscopy details. When there was disagreement (3 cases) between the assessing pathologists, cases were reviewed and a consensus diagnosis agreed. 
- Table 1a Basic characteristics of enrolled patients with polyps.

\begin{tabular}{|l|c|}
\hline All patients with polyps (\%) & $\mathbf{4 2}(\mathbf{6 5 . 6 )}$ \\
\hline Male $\mathrm{n}(\%)$ & $29(69)$ \\
\hline Mean age (years) & 69 \\
\hline Height $(\mathrm{m})$ & 1.72 \\
\hline Weight $(\mathrm{kg})$ & 84.45 \\
\hline Indication $\mathbf{n}(\%)$ & \\
\hline Screening & $21(50)$ \\
\hline Surveillance & $21(50)$ \\
\hline
\end{tabular}

- Table 1b Procedural time differences between those with and without polyps who were recruited to the study pre-colonoscopy.

\begin{tabular}{|l|l|l|l|}
\hline All patients $\mathbf{n = 6 4}$ (\%) & $\begin{array}{l}\text { Polyps 42 } \\
\text { (65.6) }\end{array}$ & $\begin{array}{l}\text { No polyps } \\
\mathbf{2 2}(\mathbf{2 6})\end{array}$ & P value \\
\hline $\begin{array}{l}\text { Mean procedure time } \\
\text { (min, secs) }\end{array}$ & 36.04 & 26.05 & 0.01 \\
\hline Withdrawal (min, secs) & 25.36 & 15.33 & 0.002 \\
\hline min, minutes; secs, seconds & & \\
\hline
\end{tabular}

- Table 2 Polyp and polypectomy characteristics from the 57 polyps included for analysis.

\begin{tabular}{|c|c|c|c|}
\hline & $\begin{array}{l}\text { Complete re- } \\
\text { section rate } \\
\mathrm{n} / \mathrm{N}(\%)\end{array}$ & $95 \% \mathrm{Cl}$ & $\begin{array}{l}P \\
\text { value }\end{array}$ \\
\hline Overall complete resection & $49 / 57(86)$ & $75-93$ & \\
\hline \multicolumn{4}{|l|}{ Histology } \\
\hline Hyperplastic & $14 / 17(82.4)$ & $60-95$ & \multirow[t]{2}{*}{0.61} \\
\hline Adenomatous & $35 / 40(87.5)$ & $75-95$ & \\
\hline \multicolumn{4}{|l|}{ Size $(\mathrm{mm})$} \\
\hline$\leq 3$ & $19 / 21(90.5)$ & $73-98$ & \multirow[t]{3}{*}{0.26} \\
\hline $4-5$ & $14 / 15(93.3)$ & $74-99$ & \\
\hline $6-7$ & $16 / 21(76.2)$ & $55-91$ & \\
\hline \multicolumn{4}{|l|}{ No of bites } \\
\hline 1 & $25 / 30(83.3)$ & $67-94$ & \multirow[t]{3}{*}{0.57} \\
\hline $2-3$ & $21 / 23(91.3)$ & $75-99$ & \\
\hline$\geq 4$ & $3 / 4(75)$ & $27-98$ & \\
\hline \multicolumn{4}{|l|}{ Location } \\
\hline Right colon & $20 / 23(87)$ & $69-97$ & \multirow[t]{3}{*}{0.86} \\
\hline Left colon (except rectum) & $20 / 24(83.3)$ & $65-95$ & \\
\hline Rectum & $9 / 10(90)$ & $63-99$ & \\
\hline
\end{tabular}

\section{Sample size}

Other comparative published studies looking at cold forceps polypectomy techniques for diminutive to small polyps have had polyp numbers between fifty-four and one hundred and seventeen $[10,11,13,22]$. The sample size was determined to be between 50 and 100 polyps based on the fact that it was an achievable figure within the scope of the project and local clinical service that should yield a relatively narrow confidence interval for CRR.

\section{Statistics}

SPSS version 24 was used for all statistical calculations. Chisquare tests were used for the counted variables and independent-sample t-tests for the measured ones.

\section{Results}

Sixty-four patients were recruited after screening and informed consent. All bowel preparations for recruited patients were good or adequate. Forty-two patients had a total of 60 polyps resected $(\triangleright$ Table $1 \mathbf{1 a})$. Three polyps were excluded from analysis (inflammatory or post inflammatory polyps) leaving 57 polyps in the final analysis. Patients were divided into 2 groups, those with polyps and those without polyps ( $\downarrow$ Table 1b) for the purpose of determining procedural time differences.

Differences were observed between the 2 groups in respect to procedural and withdrawal times ( $>$ Table 1b). Mean polypectomy time using the CBPP technique was 118.6 seconds with a range between 57 and 229 seconds. There were no immediate or delayed adverse events secondary to the polypectomy technique. Haemostatic clips were used for minor bleeds after EMR of polypectomy site in 2 cases.

Overall the CRR was $86 \%$ (95\% Confidence Interval (CI): 75 $93 \%$ ) ( Table 2). Polyp location, histology and number of biopsies required for complete visual removal, did not affect CRR. No polyps were excluded from the study because of anatomical location or morphology. There was a $100 \%$ retrieval of polyp tissue using this polypectomy technique, which is the same as other studies into cold forceps polypectomy. The 6- and 7-mm polyps had a complete resection rate of $76.2 \%$. Polyps $\leq 5 \mathrm{~mm}$ polyps had a complete resection rate of $91.7 \%(P=0.105)$ (> Fig. 5).

\section{Discussion}

The complete and safe removal of polyps during colonoscopy is crucial yet there were few published studies or guidelines for colonoscopists to determine how diminutive and small polyps should be removed until recent ESGE guideline development [17]. Through this study we aimed to assess the feasibility and effectiveness of a pre lift and cold biopsy forceps for polypectomy. We also wished to see how this technique compares to other more commonly used methods such as cold snare and cold biopsy alone from previous studies. 


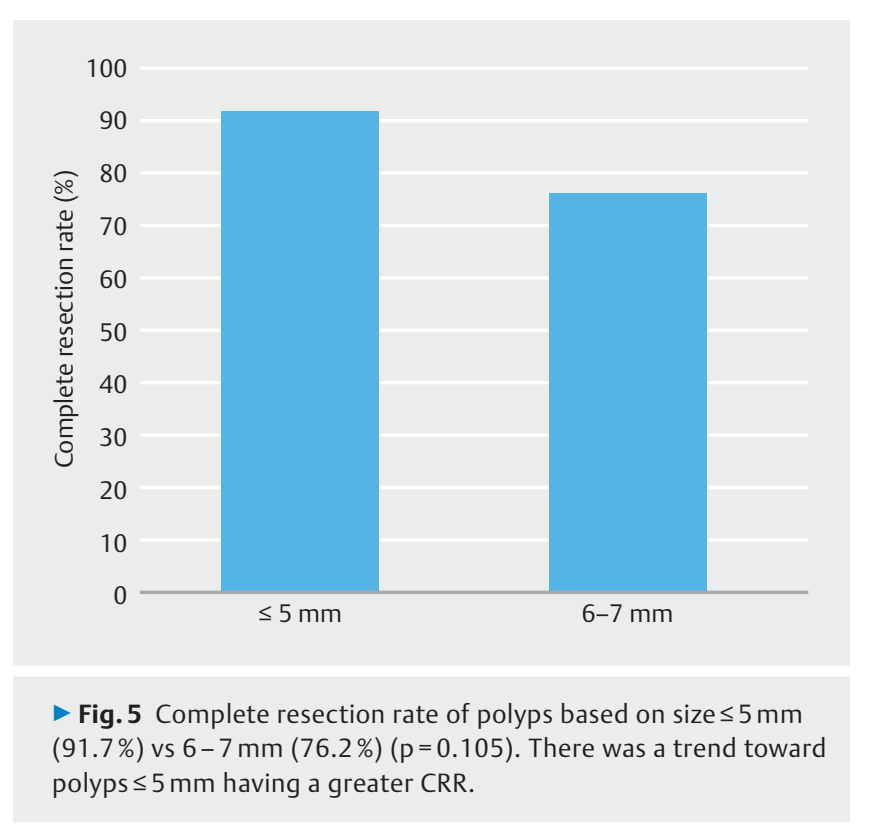

The cold snare technique has been shown to be safe for lesions $<10 \mathrm{~mm}$ [19], as well as time efficient (when compared to cold forceps) $[10,14]$. Tissue retrieval is variable with retrieval rates found to be between $81 \%$ and $100 \%[23,24]$. This is likely to be variable as the resected tissue usually does not remain fixed to the snare and has the potential to be lost in fluid and debris within the colon. Lee et al report a complete histological resection rate for diminutive polyps $(<5 \mathrm{~mm})$ using cold snare at $93.2 \%$, however there was also failed retrieval of $6.8 \%$ [10].

Cold forceps technique has been shown to be safe in a number of trials $[10,11,13,19]$. In recent studies its effectiveness has been variable. Complete histological resection varies widely between 39 and $90.7 \%[10,11,13]$. However, retrieval rates are greater than other polypectomy methods and have been reported at $100 \%,[14,24]$. The excellent retrieval rate probably reflects that resected tissue remains retained within the forceps and no specific retrieval techniques are necessary.

A pre-injection to lift the mucosa limits the chance of complications such as perforation or bleeding in endomucosal resection of polyps [15-28]. Pre-injection solution may contain a dye such as indigo carmine or methylene blue. The use of indigo carmine in chromoendoscopy has been shown to enhance mucosal features and delineate histologically normal from abnormal mucosa in cold polypectomy [11]. Indigo carmine was effectively used by Jung et al to increase complete histological resection of diminutive polyps with the cold forceps technique up to $90.7 \%$ [11].

Our small study showed that a pre-lift prior to the use of cold forceps for the removal of diminutive polyps $(\leq 5 \mathrm{~mm})$ takes effectiveness of cold forceps polypectomy to a CRR of $91.7 \%$. We think there are 3 key reasons as to why this occurs. Firstly, the use of indigo carmine in lifting solution helps delineate normal from polypoid mucosa ensuring that residual tissue is resected. Second, the separation of mucosa from submucosa with lifting mix seems to allow for a greater amount of mucosa including polyp tissue, to be sheared away with each bite of the biopsy forceps. Thirdly, the adrenaline in the pre-injection mix helps limit bleeding and allows the endoscopist the ability to find residual polyp tissue without excess washing of the site.

The current study had significant limitations. Firstly, the study size was small and from a single centre (Gloucestershire NHS trust). Second, the colonoscopists were highly experienced and practiced in this technique. It was not determined how easy this technique could be taught and employed with other endoscopists.

Third, this was a small observational study rather than a randomised controlled trial and comparisons can only be made to other techniques from prior studies.

Although highly effective with a complete resection rate of $86 \%$, and $100 \%$ retrieval rate, the time taken for polypectomy is significantly more than that seen with cold biopsy and cold forceps polypectomy in another study [10]. The mean polypectomy time being 118.6 seconds with a significant increase in overall procedure and withdrawal times when compared to the group with no polyps included in the study.

\section{Conclusion}

Ultimately this study builds on the evidence supporting recently developed guidelines [17] that cold snare polypectomy for diminutive polyps is more cost and time effective with a slightly superior completeness of resection. It is hard to place a value on this extra time taken for small gains in retrieval that cold forceps polypectomy provides. However, diminutive polyps have been shown to harbour advanced histology and even cancers. In an era where the quality of colonoscopy and completeness of polypectomy is crucial this novel technique is worth consideration in appropriate polyps, especially where cold snare may be technically difficult. This study also highlights the role of sub-mucosal pre-lift to improve CRR and would be worth studying further in relation to cold snare polypectomy.

Time limitations and cost will always be considered when choosing the most appropriate polypectomy technique, however effective and adequate polypectomy is critical to ensure optimal protection from interval cancers and should be the main consideration. Studies into polypectomy techniques are limited and it is clear that additional data and review of polypectomy methods need to be undertaken. This is crucial to help colonoscopists determine the optimal method for the removal of colorectal polyps and continue to improve the quality of our patient's colonoscopies.

\section{Acknowledgements}

Olympus UK kindly supported the study with provision of 10 $\mathrm{mm}$ and 15-mm Olympus Snaremaster snares.

The authors acknowledge the Gloucestershire NHS trust bowel cancer screening nurses and Cheltenham General Hospital Endoscopy department nursing staff. 
Competing interests

None

References

[1] Winawer SJ, Zauber AG, Ho MN et al. Prevention of colorectal cancer by colonoscopic polypectomy. The National Polyp Study Workgroup. N Engl J Med 1993; 329: 1977 -1981

[2] Zauber AG, Winawer S], O'Brien M] et al. Colonoscopic polypectomy and long-term prevention of colorectal-cancer deaths. N Engl J Med 2012; 366: 687-696

[3] Atkin WS, Edwards R, Kralj-Hans I et al. Once-only flexible sigmoidoscopy screening in prevention of colorectal cancer: a multicentre randomised controlled trial. Lancet 2010; 375: 1624-1633

[4] Farrar WD, Sawhney MS, Nelson DB et al. Colorectal cancers found after a complete colonoscopy. Clin Gastroenterol Hepatol 2006; 4: $1259-1264$

[5] Martinez ME, Baron JA, Lieberman DA et al. A pooled analysis of advanced colorectal neoplasia diagnoses after colonoscopic polypectomy. Gastroenterology 2009; 136: $832-841$

[6] Pabby A, Schoen RE, Weissfeld JL et al. Analysis of colorectal cancer occurrence during surveillance colonoscopy in the dietary Polyp Prevention Trial. Gastrointest Endosc 2005; 61: 385-391

[7] Leung K, Pinsky P, Laiyemo AO et al. Ongoing colorectal cancer risk despite surveillance colonoscopy: the Polyp Prevention Trial Continued Follow-up Study. Gastrointest Endosc 2010; 71: 111-117

[8] Chandran S, Parker F, Vaughan R et al. The current practice standard for colonoscopy in Australia. Gastrointest Endosc 2014; 79: 473-479

[9] Singh N, Harrison M, Rex DK. A survey of colonoscopic polypectomy practices among clinical gastroenterologists. Gastrointest Endosc 2004; 60: 414-418

[10] Lee CK, Shim JJ, Jang JY. Cold snare polypectomy vs. Cold forceps polypectomy using double-biopsy technique for removal of diminutive colorectal polyps: a prospective randomized study. Am J Gastroenterol 2013; 108: $1593-1600$

[11] Jung YS, Park JH, Kim H] et al. Complete biopsy resection of diminutive polyps. Endoscopy 2013; 45: 1024-1029

[12] Park SK, Ko BM, Han JP et al. A prospective randomized comparative study of cold forceps polypectomy by using narrow-band imaging endoscopy versus cold snare polypectomy in patients with diminutive colorectal polyps. Gastrointest Endosc 2016; 83: 527 - 532

[13] Efthymiou M, Taylor AC, Desmond PV et al. Biopsy forceps is inadequate for the resection of diminutive polyps. Endoscopy 2011; 43: $312-316$
[14] Raad D, Tripathi P, Cooper G et al. Role of the cold biopsy technique in diminutive and small colonic polyp removal: a systematic review and meta-analysis. Gastrointest Endosc 2016; 83: 508-515

[15] Church JM. Clinical significance of small colorectal polyps. Dis Colon Rectum 2004; 47: 481 - 485

[16] Gupta N, Bansal A, Rao D et al. Prevalence of advanced histological features in diminutive and small colon polyps. Gastrointest Endoscop 2012; 75: 1022 - 1030

[17] Ferlitsch M, Moss A, Hassan C et al. Colorectal polypectomy and endoscopic mucosal resection (EMR): European Society of Gastrointestinal Endoscopy (ESGE) Clinical Guideline. Endoscopy 2017; 49: $270-297$

[18] Tsai FC, Strum WB. Prevalence of advanced adenomas in small and diminutive colon polyps using direct measurement of size. Digest Dis Scie 2011; 56: $2384-2388$

[19] Repici A, Hassan C, Vitetta E et al. Safety of cold polypectomy for $<10 \mathrm{~mm}$ polyps at colonoscopy: a prospective multicenter study. Endoscopy 2012; 44: 27-31

[20] Steele RJ, Pox C, Kuipers E] et al. European guidelines for quality assurance in colorectal cancer screening and diagnosis. First EditionManagement of lesions detected in colorectal cancer screening. Endoscopy 2012; 44: (Suppl. 03): SE140 - 150

[21] on Elm E, Altman DG, Egger M et al. Strengthening the Reporting of Observational Studies in Epidemiology (STROBE) statement: guidelines for reporting observational studies. BMJ (Clinical research ed.) 2007; 335: $806-808$

[22] Ichise $Y$, Horiuchi A, Nakayama $Y$ et al. Prospective randomized comparison of cold snare polypectomy and conventional polypectomy for small colorectal polyps. Digestion 2011; 84: 78 - 81

[23] Deenadayalu VP, Rex DK. Colon polyp retrieval after cold snaring. Gastrointest Endosc 2005; 62: 253-256

[24] Komeda Y, Suzuki N, Sarah M et al. Factors associated with failed polyp retrieval at screening colonoscopy. Gastrointest Endosc 2013; 77: $395-400$

[25] Buchner AM, Guarner-Argente C, Ginsberg GG. Outcomes of EMR of defiant colorectal lesions directed to an endoscopy referral center. Gastrointest Endosc 2012; 76: 255-263

[26] Church JM. Experience in the endoscopic management of large colonic polyps. ANZ J Surg 2003; 73: 988 - 995

[27] Ferrara F, Luigiano C, Ghersi S et al. Efficacy, safety and outcomes of 'inject and cut' endoscopic mucosal resection for large sessile and flat colorectal polyps. Digestion 2010; 82: 213-220

[28] Moss A, Bourke M], Williams S] et al. Endoscopic mucosal resection outcomes and prediction of submucosal cancer from advanced colonic mucosal neoplasia. Gastroenterology 2011; 140: 1909-1918 